\title{
Statistical analysis of solid waste composition data: Arithmetic mean, standard
} deviation and correlation coefficients

Edjabou, Maklawe Essonanawe; Martín-Fernández, Josep Antoni; Scheutz, Charlotte; Astrup, Thomas Fruergaard

Published in:

Waste Management

Link to article, DOI:

10.1016/j.wasman.2017.08.036

Publication date:

2017

Document Version

Peer reviewed version

Link back to DTU Orbit

Citation (APA):

Edjabou, M. E., Martín-Fernández, J. A., Scheutz, C., \& Astrup, T. F. (2017). Statistical analysis of solid waste composition data: Arithmetic mean, standard deviation and correlation coefficients. Waste Management, 69, 1323. https://doi.org/10.1016/j.wasman.2017.08.036

\section{General rights}

Copyright and moral rights for the publications made accessible in the public portal are retained by the authors and/or other copyright owners and it is a condition of accessing publications that users recognise and abide by the legal requirements associated with these rights.

- Users may download and print one copy of any publication from the public portal for the purpose of private study or research.

- You may not further distribute the material or use it for any profit-making activity or commercial gain

- You may freely distribute the URL identifying the publication in the public portal 
Statistical analysis of solid waste composition data:

4 arithmetic mean, standard deviation and correlation coefficients

6

$7 \quad$ Maklawe Essonanawe Edjabou ${ }^{1 *}$, Josep Antoni Martín-

$8 \quad$ Fernández $^{2}$, Charlotte Scheutz ${ }^{1}$, Thomas Fruergaard Astrup ${ }^{1}$

9

10 1) Department of Environmental Engineering, Technical

11 University of Denmark, 2800 Kgs. Lyngby, Denmark

12 2) Dept. Computer Science, Applied Mathematics and

13 Statistics, University of Girona, Campus Montilivi (P4), E-

14 17071 Girona, Spain

15

16

17 
1 Title of paper: Statistical analysis of solid waste composition data: Arithmetic mean, standard 2 deviation and correlation coefficients

3 The core findings of the paper:

4

5

- Data for waste fraction compositions represent closed datasets that require special attention in case of

6 statistical analysis

7

- Classical statistics are ill-suited to data for waste fraction compositions

8

- Isometric log-ratio coordinates enable appropriate transformation of waste fraction compositional data prior to

9 statistical analysis. 


\section{Abstract}

19 Data for fractional solid waste composition provide relative

20 magnitudes of individual waste fractions, the percentages of

21 which always sum to 100 , thereby connecting them

22 intrinsically. Due to this sum constraint, waste composition

23 data represent closed data, and their interpretation and analysis

24 require statistical methods, other than classical statistics that are

25 suitable only for non-constrained data such as absolute values.

26 However, the closed characteristics of waste composition data

27 are often ignored when analysed. The results of this study

28 showed, for example, that unavoidable animal-derived food

29 waste amounted to $2.21 \pm 3.12 \%$ with a confidence interval of (-

$304.03 ; 8.45)$, which highlights the problem of the biased negative

31 proportions. A Pearson's correlation test, applied to waste

32 fraction generation ( $\mathrm{kg}$ mass), indicated a positive correlation

33 between avoidable vegetable food waste and plastic packaging.

34 However, correlation tests applied to waste fraction

35 compositions (percentage values) showed a negative

36 association in this regard, thus demonstrating that statistical

37 analyses applied to compositional waste fraction data, without

38 addressing the closed characteristics of these data, have the

39 potential to generate spurious or misleading results. Therefore,

40 "compositional data should be transformed adequately prior to

41 any statistical analysis, such as computing mean, standard

42 deviation and correlation coefficients. 
44 Keywords:

45 Waste composition

46 Compositional data analysis

47 Isometric log ratio

48 Variation array

49

Page $\mathbf{3}$ of $\mathbf{3 5}$ 


\section{Introduction}

$51 \quad$ Knowledge of the individual material fractions in waste

52 represents the basis of any waste management system planning

53 and development (Christensen, 2011). This information is also

54 crucial for establishing baselines and evaluating the

55 effectivness of environmental policies. Generally, the

56 fractional composition of waste is obtained by conducting

57 waste fraction composition studies and is usually provided as

58 weight percentages of selected materials such as paper, plastic,

59 metal, food waste, etc. (Lagerkvist et al., 2011). Independently

60 of waste characterisation methods, waste fraction composition

61 arithmetic mean and standard deviation are usually provided

62 (European Commission, 2004), thus ignoring the inherent

63 structure of data for waste fraction compositions (Pawlowsky-

64 Glahn et al., 2015). Here, the standard deviation measures the

65 'spread' of the estimated arithmetic mean (Reimann et al., 66 2008).

67 Waste fraction composition data are 'closed' datasets 68 because of the limited sample space (from 0 to 100 i.e. 69 percentages). This is known as the 'constant sum constraint' 70 (Aitchison, 1986), where the percentage of one waste fraction 71 depends on the ratio of the other waste fractions included in 72 the sampled waste stream. Consequently, the percentages of 73 waste fractions are linked to each other intrinsically. Therefore, 
74 univariate analysis (composition of waste fractions analysed

75 separately) of waste fraction compositions is inappropriate,

76 because it violates the fundamental assumption of

77 independence of observations (Pawlowsky-Glahn et al., 2015).

78 For example, Hanc et al. (2011) studied the composition of

79 household bio-waste and reported that the yearly percentage of

80 grass amounted to $27.6 \pm 30.8 \%$ in single-family areas. The

81 mean was $27.6 \%$ and its standard deviation $30.8 \%$. The

82 resulting confidence interval $(2 *$ standard deviation) of the

83 mean was the interval $(-34.0 \% ; 89.2 \%)$, which covers negative

84 percentages, although the values cannot be negative in this

85 case. This problem is described as 'intervals covering negative

86 proportions' (Pawlowsky-Glahn et al., 2015). An increase in

87 the percentage of one waste fraction leads to a decrease in the

88 percentage of another fraction and vice versa, because the sum

89 of the percentage of individual waste fraction is fixed

90 (Reimann et al., 2008).

91 Data for waste fraction compositions refer to

92 compositional data, which arise in many fields such as

93 geochemistry (mineral composition of rocks), medicine (blood

94 composition) and archaeology (ceramic compositions)

95 (Aitchison, 1994). Here, compositional data carry relative

96 information or a ratio and add up to a constant (1 for

97 proportion, 100 for percentage and $10^{4}$ for ppm (parts per

98 million)) (Aitchison, 1986; Buccianti and Pawlowsky-Glahn, 
99 2011). As further examples, chemical compositionwaste water

100 content, etc. also represent closed datasets (see Aitchison,

101 1994).

102 Arithmetic mean and standard deviation are based on the

103 assumption that observations follow normal or symmetrical

104 statistical distribution (Reimann et al., 2008). Numerous -

105 mainly statistical-based - studies show that these estimates are

106 affected considerably when data exhibit small deviations from

107 normal distribution (Reimann et al., 2008; Wilcox, 2012). On

108 the other hand, environmental data including waste fraction

109 composition are often skewed (Reimann et al., 2008), in which

110 case the resulting descriptive statitics may be biased and

111 subsequently lead to wrong conclusions. Nevertheless, most

112 waste characterisation studies report the arithmetic mean and

113 standard deviation of waste fraction compositions, ignoring the

114 natural structure of compositional data (e.g. Hanc et al., 2011;

115 Edjabou et al., 2015; Naveen et al., 2016).

116 Despite the importance of arithmetic mean and standard

117 deviation estimates in relation to waste composition, no

118 attempts have been made to address the quality of these

119 estimates.

120 Correlation coefficients between individual waste

121 fractions are commonly computed in order to investigate

122 relationships between material fractions in mixed waste (e.g.

123 Alter, 1989; Hanc et al., 2011; Naveen et al., 2016), but they 
124 are also used to evaluate the quality and the source of elements

125 in chemical compositions of municipal solid waste (e.g. Hanc

126 et al., 2011; Naveen et al., 2016). An illustrative example is the

127 correlation between food waste and packaging materials such

128 as paper, board, plastic and metal. For example, Alter (1989)

129 claimed that an increase in food packaging may decrease food

130 waste occuring in housholds. In contrast, Williams et al. (2012)

131 argued that 20 to $25 \%$ of food waste generation is due to

132 packaging. Notwithstanding the relevance of correlation

133 analysis applied to waste fraction compositions, the

134 contradictory results of correlation coefficients (see Alter,

1351989 and Williams, 2012) still require explanation.

136 Overall, computing arithmetic means, standard deviations

137 and correlation coefficients for material fraction compositions

138 may lead to biased results (Aitchison, 1994; Filzmoser and

139 Hron, 2008). Additionally, uncertainty analysis (e.g. Monte

140 Carlo analysis) of these datasets can be a source of concern

141 when the issue of independence between material fraction

142 compositions is either ignored or poorly addressed ( $\mathrm{Xu}$ and

143 Gertner, 2008).

144 Several studies have attempted to analyse waste

145 composition data by applying log transformation (Chang and

146 Davila, 2008; Dahlén et al., 2007) or log-logistic

147 transformation (Milke et al., 2008). However, the

148 compositional nature of waste fraction composition remains 
149 intrinsic for waste fraction composition data.

150 The overall aim of this paper is to demonstrate why

151 fractional waste composition data should be transformed

152 appropriately prior to statistical analysis. We compared some

153 commonly encountered classical statistics applied to waste

154 fraction compositions data and the compositional data analysis

155 technique based on log-ratio coordinates, by analysing the

156 fractional compositions of residual household waste in

157 Denmark.

$158 \quad 2$ Methods and materials

$159 \quad 2.1$ Study area and waste sampling analysis

160 We analysed residual household waste collected from 779

161 single-family areas in Denmark. In these residential areas,

162 paper, board, gardening waste, household hazardous waste,

163 waste electrical and electronic equipment (WEEE) and bulky

164 waste were source-segregated.

165 The residual household waste was generated over a one-

166 week period, collected directly from households and kept

167 separately for each household. Each waste bin was labelled

168 with the address of the household from where the waste was

169 collected. The waste bins were sealed tightly, to prevent

170 mixing of waste during transportation to the sorting facility.

171 Each household waste bin was weighed and sorted separately,

172 thereby enabling us to obtain data for residual household waste

173 for each house. 
174 Collected residual household waste was sorted manually

175 into the following waste fractions (Table 1): (1) avoidable

176 vegetable food waste (AV), (2) avoidable animal-derived food

177 waste (AA), (3) unavoidable vegetable food waste (UV), (4)

178 unavoidable animal-derived food waste (UA), (5) paper \&

179 board (Paper or $\mathrm{Pa}$ ), (6) plastic packaging (Plastic or Pl), (7)

180 metal packaging (Metal or $\mathrm{Me}$ ) and (8) other waste fractions

181 (Others or Ot). In the present study, 'paper' refers to paper and

182 board packaging. 'Others' refers to all other waste materials

183 not included in the first seven waste fractions in Table 1.

184 Avoidable food waste constitutes food and drinks that could

185 have been eaten but instead have been disposed of. It consists

186 of avoidable animal-derived (AA) and vegetable (AV) food

187 waste. Unavoidable food waste is food that is not edible under

188 normal conditions (Edjabou et al., 2016) and consists of

189 unavoidable animal-derived (UA) and vegetable (UV) food

190 waste. The detailed sub-fractions included in these waste

191 fractions are presented in Table 1.

192 In this study, waste fraction composition represents the

193 fractional composition of waste fractions expressed in

194 percentage terms. Waste fraction generation rates are the mass

195 of individual waste fractions in $\mathrm{kg}$ per capita per week. 
199

200

201

202

203

204 211 transformed of waste fraction composition datasets. Therefore,

212 for each dataset (waste fraction compositions and log

213 transformed), we calculated the total variance and the 214 percentage thereof.

\subsection{Overview of statistical analysis: classical statistical} analysis

For this study, we computed (1) the arithmetic mean (Mean) of waste fraction compositions, (2) log-transformed (log-Mean), and its back-transformed $(\exp (\log -M e a n))$ shown as Mean-log. We also computed standard deviation (SD), logtransformed (SD-log) and coefficient of variation (CV).

Noticeably, any covariance matrix has in its diagonal the variance ('var') of each variable. The sum of this diagonal, also known as the 'trace' of the matrix, is equal to total variance (Härdle and Simar, 2015) and holds in raw and log

We also investigated the relationship between waste fractions by applying Pearson's correlation analysis to raw and log-transformed data for waste fraction compositions (in percentage) and generation rates ( $\mathrm{kg}$ waste fraction per capita per week). However, this paper focuses mainly on the waste fraction composition dataset.

\subsection{Compositional data analysis: isometric log-ratio}

\section{approach}

We applied statistical analysis to isometric log-ratio (ilr) 
224 coordinates, computed based on the sequential binary partition

225 (SBP) (Egozcue et al., 2003). This approach transforms data

226 for waste fraction compositions into an unconstrained, real

227 dataset, thus enabling the use of classical statistics (Filzmoser

228 and Hron, 2008). This, for example, may mean that instead of

229 a dataset with a list of percentages that should always sum up

230 to 100 for each observation, the isometric log-ratio transforms

231 waste fraction composition data into a list of values that are

232 independent and should not sum up to a constant.

233 Similar to classical log transformation, the isometric log-

234 ratio requires that the data should not contain 'zero values'.

235 For this study, a waste 'zero value' means that a household did

236 not generate any waste during this sampling week. Thus, we

237 assumed that zero values were due to the experimental design,

238 mainly the 'time limit' of the sampling campaign. For this

239 reason, zero values were replaced, using 'imputation based on

240 the log-ratio expectation-maximisation (EM) algorithm'

241 (lrEM) in the zCompositions package (Palarea-Albaladejo and

242 Martín-Fernández, 2015), which comprises four steps: (1)

243 dataset selection, which can be the waste fraction composition

244 (percentage) or generation rate (kg waste fraction per capita

245 per week). For this study, we used the waste fraction

246 generation rate; nevertheless, the function lrEM is based on

247 compositional data analysis technique and therefore ensures

248 equivalent results regardless of datasets. (2) The descriptive 
249 analysis of the zero values was performed using the function

250 zPattern in the zCompositions package. As a result, a graphical

251 representation of the relative frequencies of zero for each

252 waste fraction is provided. (3) Threshold (the detection limit)

253 values should be defined prior to zero replacement. A single

254 value for all waste fractions or varying values can be selected.

255 For this study, a single threshold value was set at $10 \mathrm{~g}$, which

256 is the minimum weight of the weighing scale used for the

257 waste sampling campaign. (4) The new dataset contained non-

258 zero values. In practice, the function $1 r E M$ substitutes an

259 observation $\boldsymbol{x}$ with a value of zero by a random observation $\boldsymbol{y}$

260 in the interval between zero and the threshold value (see

261 Palarea-Albaladejo and Martín-Fernández, 2015, for detailed

262 mathematics underpinning zCompositions).

263 Seven coordinates $\left(\mathrm{ilr}_{1}\right)$ were computed corresponding to

$264 D-1$ numbers of partitions. Here, $D$ was eight, namely the

265 number of waste fractions shown in Table 1. The first ilr

266 coordinate was computed by dividing the eight fractions into

267 two groups: food waste and non-food waste. Subsequently,

268 each of the two groups was divided further until each group

269 was represented by one single waste fraction, as indicated in

270 Table 2, where $(+1)$ refers to the group in the numerator, while

$271(-1)$ is the group appearing in the denominator. 
275 The ilr coordinates were computed based on the formulas

276 shown in Eqs. (1-7). Eq. (1) computed the coordinate (ilr $\left._{1}\right)$

277 between food waste and non-food waste. Eqs. (2-4) computed

278 the coordinates ilr $_{2}$ (vegetable versus animal food waste), ilr $_{3}$

279 (avoidable versus unavoidable vegetable food waste) and $\mathrm{ilr}_{4}$

280 (avoidable versus unavoidable animal-derived food waste).

281 Furthermore, the coordinate ilr $\mathrm{r}_{5}$ (paper and metal versus plastic

282 and other) was calculated in Eq. (5), the coordinate ilr 6

283 between paper and metal was derived in Eq. (6) and the

284 coordinate il $_{7}$ between plastic and other in Eq. (7).

$\operatorname{ilr}_{1}\{\mathrm{AV}, \mathrm{UV}, \mathrm{AA}, \mathrm{UA}\} \mathrm{vs} .\{\mathrm{Pa}, \mathrm{Me}, \mathrm{Pl}, \mathrm{Ot}\}=$

$\sqrt{\frac{4 \times 4}{4+4}} \mathrm{LN} \frac{\sqrt[4]{\text { AVXUAXAAXUA }}}{\sqrt[4]{\text { PaXMeXPlX0t }}}$

$286 \quad(1)$

$287 \operatorname{ilr}_{2}\{$ AV, UV $\}$ vs. $\{$ AA, UA $\}=\sqrt{\frac{2 \times 2}{2+2}} \mathrm{LN} \frac{\sqrt[3]{\text { AVXUV }}}{\sqrt[2]{\text { AAXUA }}}(2)$

$288 \quad$ ilr ${ }_{3}\{$ AV $\}$ vs. $\{$ UV $\}=\sqrt{\frac{1 \times 1}{1+1}} \operatorname{LN} \frac{\sqrt[1]{\text { AV }}}{\sqrt[1]{\text { UV }}}(3)$

$289 \operatorname{ilr}_{4}\{$ AA $\}$ vs. $\{$ UA $\}=\sqrt{\frac{1 \times 1}{1+1}} \mathrm{LN} \frac{\sqrt[1]{\mathrm{AA}}}{\sqrt[1]{\mathrm{UA}}}(4)$

$290 \quad \operatorname{ilr}_{5}\{\mathrm{~Pa}, \mathrm{Me}\}$ vs. $\{\mathrm{Pl}, \mathrm{Ot}\}=\sqrt{\frac{2 \times 2}{2+2}} \mathrm{LN} \frac{\sqrt[2]{\mathrm{PaXMe}}}{\sqrt[n]{\mathrm{Pl} \times 0 \mathrm{t}}}(5)$

$291 \operatorname{ilr}_{6}\{$ Pa $\}$ vs. $\{$ Me $\}=\sqrt{\frac{1 \times 1}{1+1}} \operatorname{LN} \frac{\sqrt[1]{\mathrm{Pa}}}{\sqrt[11]{\mathrm{Me}}}(6)$

$292 i \operatorname{lr}_{7}\{P l\} v s .\{O t\}=\sqrt{\frac{1 \times 1}{1+1}} L N \frac{\sqrt[1]{P l}}{\sqrt[1]{O t}}(7)$

293 Here, LN stands for the natural logarithm, and the other 
294 abbreviations refer to the waste fractions presented in Table 1.

$295 \mathrm{~Pa}$ refers to paper and board, $\mathrm{Pl}$ to plastic packaging, Me to

296 metal packaging and Ot to other.

297 The CoDa technique uses the geometric mean of the dataset,

298 which is the 'back-transformed' value of the ilr-arithmetic

299 mean and is calculated as follows:

300

$g_{m}(x)=\left[\prod_{i=1}^{D} x_{i}\right]^{1 / D}=\exp \left[\frac{1}{D} \sum_{i=1}^{D} \operatorname{LN}\left(x_{i}\right)\right](8)$

301 where $g_{m}(x)$ is the geometric mean and $D$ is the number of

302 waste fractions $\left(x_{i}\right)$ involved. The natural logarithm is

303 abbreviated as $L N\left(x_{i}\right)$ and its inverse is abbreviated as $\exp \left(x_{i}\right)$.

304 The back transformation of the isometric log-ratio

305 coordinates is calculated simply by reversing the original

306 transformation (Egozcue et al., 2003). The general formula for

307 the back transformation of the isometric log-ratio coordinate

308 (ilr $\left.{ }^{-1}\right)$ is provided as follows (Felipe et al., 2016):

$309 i l r^{-1}=C(\exp (x * \psi))$

310 where ilr $^{-1}$ is the back transformation, $\mathbf{x}$ is the simulated value

311 for the transformation (ilr), $\psi$ is the matrix constructed from

312 the sequential binary partition given in Eqs ( 1 to 7 ) and $C$ is

313 the closure operation that provides a closed dataset.

314 Total variance (totvar $(\boldsymbol{x})$ ) is introduced to provide a global

315 measure of spread (Pawlowsky et al., 2008) and measures the

316 variation between individual waste fraction compositions

317 included in the dataset. Total variance is computed as: 
$318 \operatorname{totvar}(x)=\frac{1}{D} \sum_{i=1}^{D-1} \quad \sum_{j=i+1}^{D} \operatorname{var}\left(L N \frac{x_{i}}{x_{j}}\right)(10)$

319 The relationship between pairs of waste fractions is

320 analysed by means of a variation array, calculated as:

$\mathrm{A}=\left[\begin{array}{cccc}0 & \mathrm{v}_{12} & \ldots & \mathrm{v}_{1 \mathrm{D}} \\ \mathrm{e}_{21} & 0 & \ldots & \mathrm{v}_{2 \mathrm{D}} \\ \vdots & \vdots & \ddots & \vdots \\ \mathrm{e}_{\mathrm{D} 1} & \mathrm{e}_{\mathrm{D} 2} & \ldots & 0\end{array}\right]$

(11) where,

322

$e_{i j}=E\left(\ln \frac{x_{i}}{x_{j}}\right)(12) \quad$ and $\quad v_{i j}=\operatorname{var}\left(\ln \frac{x_{i}}{x_{j}}\right)(13)$

323 The variation array (Aitchison, 1986) was introduced to

324 provide a solution to the problem of computing correlation

325 coefficients for compositional data. We computed the variation

326 array using both waste fraction compositions and generation

327 rates.

$328 \quad 2.4$ Software for data analysis

329 First, the data were explored and zero values imputed

330 using the R package 'zCompositions' (Palarea-Albaladejo and

331 Martín-Fernández, 2015). The ilr coordinates and their back

332 transformation, as well as variation array, were computed with

333 CoDaPack (Thió-Henestrosa and Comas-Cufi, 2011).

334 Thereafter, the most commonly used methods employed for

335 describing and analysing waste data, such as mean, standard

336 deviation, coefficients of variation and correlation tests

337 (European Commission, 2004), were carried out in R ( $\mathrm{R}$ Core

338 Team, 2017). Among other packages implemented in R, the

339 'StatDA' (Filzmoser, 2015) software package was used for 
plotting.

3423 Results

$343 \quad 3.1$ Exploration of data for waste fraction compositions

344 Figure 1 displays the graphical output of the zero values

345 analysis. The columns show the analysis of zero values by

346 waste fraction. The data in Figure 1 can be grouped into two

347 parts. The first is a rectangle, containing squared boxes

348 coloured in dark grey, where waste fractions have zero values,

349 and light grey for non-zero values. The number of squared

350 boxes per column is the total combinations of zero values for

351 each household involved as a function of waste fraction. The

352 second is bar plots on the top (in dark grey), which show the

353 percentage frequency of zero values by waste fraction, whereas

354 bar plots on the right (in light grey) present the percentage

355 frequency of non-zero values for all possible combinations of

356 household and waste fractions. For example (see bar plots on

357 the top in dark grey), the percentage frequency of zero was

$358 \quad 5.35 \%$ for avoidable vegetable food waste (see first column),

359 and $2.94 \%$ for unavoidable food waste (see second column).

360 Regarding bar plots on the right-hand side of the rectangle (in

361 light grey), $64.45 \%$ of observations (households) have non-

362 zero values for all waste fractions (first line), and $8.31 \%$ are

363 non-zero values, except for the avoidable animal derived-food

364 waste fraction. 
369 Subsequently, the zero value detected was replaced prior

370 to computing the log-ratio coordinates and undertaking normal

$371 \log$ transformation. For example, the minimum values for the

372 four food waste fractions (zero values) were replaced by $5.7 \mathrm{~g}$

373 for avoidable vegetable food waste, $5.8 \mathrm{~g}$ for unavoidable

374 vegetable food waste, $2.8 \mathrm{~g}$ for avoidable animal-derived food

375 waste and $1.6 \mathrm{~g}$ for unavoidable animal-derived food waste.

376 Note that here the replaced values are between zero and $10 \mathrm{~g}$.

377 A comparison of the datasets before and after zero replacement

378 showed quite a similar distribution, demonstrating that the

379 distribution of the dataset is preserved despite containing many

380 zero values (SM Figure 1, SM Tables 2 and 3).

$381 \quad$ Figure 1 also presents a detailed overview of household

382 waste fraction generation patterns; for example, only $1.3 \%$ and

$3830.3 \%$ of the households did not generate plastic packaging or

384 paper, respectively. Noticeably, for vegetable food waste, only

$3855.2 \%$ and $2.9 \%$ of the households (see Figure 1, vertical bars)

386 did not generate AV and UV, respectively. On the other hand,

387 the percentage of households that did not generate animal-

388 derived food waste was $15.2 \%$ for AA and $14.6 \%$ for AU (see

389 Figure 1, vertical bars). These data indicate that vegetable food 
waste occurred more often than animal-derived food in Danish

391 houses.

392

$393 \quad 3.2$ Mean and standard deviation of waste fraction

394 compositions

395 The distribution of the waste fraction compositions for all

396 households is shown in Figure 2. Asymmetry is evident in the

397 boxplot of each waste fraction, because the distance from the

398 median (horizontal bar in the rectangular box) to the fifth

399 percentiles (bottom horizontal bar (Figures 2 and 4) or vertical

400 bar on the left (Figure 3)) is smaller than the distance between

401 the median to the $95^{\text {th }}$ percentiles (upper horizontal bar

402 (Figures 2 and 4) or vertical bar on the right (Figure 3)), as

403 shown in Figure 2. Thus, the data for each waste fraction were

404 positively skewed and also contained potential outliers, which

405 are defined as unusually large or small values in a sample of

406 observation (Wilcox, 2012). Here, outliers are shown in Figure

4073 as circles above the upper horizontal bar, and these outliers

408 lead to bias in the arithmetic mean and inflate the standard

409 error. Thus, robust statistical techniques have been developed

410 to deal effectively with this problem, though these methods are

411 not included in this study.

412 A detailed analysis of vegetable food waste (AV and UV)

413 is provided in Figure 3 as an example. Figures $3 a$ and $3 b$

414 illustrate a combined histogram and boxplot of waste fraction 
415 composition and log transformation for avoidable vegetable

416 food waste, while Figures $3 \mathrm{c}$ and $3 \mathrm{~d}$ represent unavoidable

417 vegetable food waste in the same regard. These figures reveal

418 asymmetric distribution despite log transformation.

419 Conversely, the ilr coordinates are distributed symmetrically

420 (see Figure 4).

421

422

Here (Figure 2)

423

Here (Table 3)

425

426

Here (Figure 3)

427

428 The arithmetic means (Mean) based on waste fraction 429 compositions sum up to 100 , whereas the arithmetic means

430 based on log-transformed (Log-mean) data sum up to 14. As a

431 result, the means of the log-transformed data are difficult to

432 interpret and apply because of the change in scale (USEPA,

433 2006). This problem could be solved by Mean-log', which is

434 obtained by 'back transforming' the log-transformed mean

435 (Mean-log=exp $(\log -$ Mean-log $))$. The arithmetic mean, log-

436 mean and mean-log were computed from an asymmetric

437 dataset, which led to biased parameter estimation and incorrect

438 results (Reimann et al., 2008; Wilcox, 2012).

439 On the contrary, the 'Mean-ilr' (mean based on isometric log- 
440 ratio coordinates) (see Table 3) was computed from

441 symmetrical data, thus suggesting that the log-ratio coordinates

442 enable a data analyst to obtain symmetric distribution of data,

443 as shown in Figure 4. Importantly, while log-ratio

444 transformation enables one to remove the constant sum

445 constraint, the 'Mean-ilr' for waste fractions sums up to 100.

446 Similar to classical statistics, robust methods have been

447 developed for the statistical analysis of compositional data

448 (Templ et al., 2011), though these methods are not included in

449 this study.

450

451

Here (Figure 4)

452

453 The standard deviation, total variance and percentage of

454 variance estimates were calculated and are shown in Table 4.

455 The results indicate that the standard deviation values for the

456 raw waste fraction composition are very high compared to

457 their corresponding arithmetic mean (Mean in Table 3). In

458 particular, the standard deviation of animal-derived food waste

459 (AA and AV) and metal packaging are higher or equal to the

460 corresponding arithmetic mean, thereby generating very high

461 variation value coefficients (e.g. $155 \%$ for metal packaging,

$462141 \%$ for unavoidable animal-derived food waste, $99 \%$ for

463 avoidable animal-derived food waste). The resulting

464 confidence intervals (Mean $\pm 2 *$ SD) were $(-6.78 ; 20.74)$ and 
$465(-4.03 ; 8.45)$ for AA and AV, respectively, including negative

466 percentages. These results highlight some of the pitfalls of

467 computing standard deviations for waste fraction

468 compositions. Moreover, the estimated percentages of

469 variances for waste fractions varied when the raw dataset for

470 waste fraction compositions (\% Var) was log-transformed (\%

471 Var-log). The highest variance percentages were found for the

472 fractions other $(\% \operatorname{Var}=31.43 \%)$ and avoidable animal-derived

473 food waste $(\% \operatorname{Var}-\log =33.24 \%)$ in raw and log-transformed

474 datasets, respectively. On the other hand, the lowest variance

475 percentages were found for unavoidable animal-derived food

476 waste $(\% \operatorname{Var}=1.47 \%)$ and other $(\% \operatorname{Var}-\log =2.74 \%)$ in the raw

477 and log-transformed datasets, correspondingly. These

478 incoherent results indicate that while log transformation could

479 indeed help to achieve normality, the calculated variance

480 becomes impossible to compare after transformation, as

481 demonstrated by Filzmoser et al. (2009).

482 Overall, it is questionable whether standard deviation

483 values are informative in the case of most sets of waste

484 composition data, due to the dual issues of non-normality and

485 the constant-sum constraint. First, the standard deviation

486 ignores the compositional nature of waste fraction composition

487 data (composition of waste fractions should add up to 100).

488 Second, most coefficients of variation (CV \%) provided in

489 Table 4 are extremely high, thus restricting their application in 
490 environmental modelling (Ciroth et al., 2013). As a solution,

491 total variance (see Eq. 9) that measures overall data

492 homogeneity (or variation) can be calculated (Pawlowsky et

493 al., 2008). Here, total variance expresses variation in the

494 dataset for each waste fraction. Thus, the contribution of each

495 waste fraction to total variation is provided in percentage terms

496 (clr-Var \%), as shown in Table 4.

497

498

\section{Here (Table 4)}

499

500 Based on the compositional data analysis technique, total

501 variance (totvar) from Eq. (9) amounted to 9.25, as shown in

502 Table 4. The waste fraction contributing to the highest

503 variation in the dataset was avoidable animal-derived food

504 waste (24.73\%), followed by unavoidable animal-derived food

505 waste (18.84\%) and metal packaging (14.81\%), suggesting that

506 the generation of these fractions by Danish households varies

507 substantially.

508 On the other hand, paper (5.27\%) and plastic packaging

$509(5.53 \%)$ made a small contribution to total variance. A possible

510 interpretation for this finding could be that metal packaging

511 materials are source-sorted by a wider variety of households

512 than paper and plastic packaging, and therefore they do not

513 vary much in the fraction that ends up in residual household

514 waste bins. However, a characterisation of total household 
515 waste including source-segregated waste (e.g. paper, metal,

516 plastic) could provide a better interpretation of these results,

517 thereby demonstrating that total variance enables the analyst to

518 compare systematically variations among waste fraction

519 compositions, which is difficult for classical standard deviation

520 and coefficient of variation estimates.

$521 \quad 3.3$ Relationship between waste fractions: Pearson's

522 correlation test

523 Table 5 presents the pairwise correlation coefficients

524 between waste fractions, computed using datasets of (1)

525 percentage composition (Percentage \%) and (2) generation

526 rates (kg/capita/week). A negative correlation coefficient

527 between waste fractions means an inverse relationship,

528 whereas a positive correlation coefficient means these fractions

529 vary in the same direction (when the value of one waste

530 fraction increases, the value of the other fraction increases too,

531 and vice versa). Moreover, while a correlation coefficient of

532 value \pm 0.5 shows a strong relationship between the two waste

533 fractions, a value of 1 means a perfect correlation. A

534 correlation coefficient is statistically significant when the p-

535 value is less than 0.5 .

536

537

Here (Table 5)

538

539 Based on the waste fraction generation rates, we found a 
540 positive and significant correlation coefficient between 'Other'

541 and the seven remaining waste fractions, as shown in Table 5.

542 In contrast, we found negative and significant correlation

543 coefficients between these fractions when the Pearson's

544 correlation test was applied to waste fraction compositions

545 (Percentage \%).

546 Figure 5 illustrates the results of the correlation test

547 applied to waste fraction composition data. Figure 5 shows that

548 the Pearson's correlation test applied to the waste fraction

549 generation dataset provided a positive correlation coefficient

550 between avoidable food waste (UA, UV, AA and AV) and

551 plastic packaging. These results are consistent with those of

552 Williams et al. (2012), suggesting that a reduction in plastic

553 packaging materials may lead to a reduction in avoidable

554 vegetable food waste. In contrast, the results of the Pearson's

555 correlation applied to the waste fraction compositions dataset

556 showed a negative correlation between the same waste

557 fractions, except for UA. These results are in good agreement

558 with those obtained by Alter (1989), and similar results were

559 obtained when the Pearson's correlation test was applied to

560 log-transformed data. Note here that the signs and the values of

561 the correlation coefficients depend on the datasets, even

562 though a Pearson's correlation test was applied to log-

563 transformed data (SM Table 1). These results pose an

564 interpretation dilemma. First, a reduction in plastic packaging 
565 may contribute to food waste reduction, due to the positive

566 correlation between these waste fractions, although, on the

567 other hand, an increase in the use of plastic packaging may

568 contribute to a reduction in household food waste because of

569 the negative correlation coefficient. Moreover, while these

570 correlation coefficients were statistically significant, their

571 estimates were somewhat different (see Figure 4 and Table 5).

572

573

574

$575 \quad 3.4$ Variation array with CoDa

576 The variation array was computed using Eq. (10) and is

577 shown in Table 6. Note that the same variation array was

578 obtained when using either the waste fractions generation rates

579 (kg/capita/week) or waste fraction compositions (percentage

$580 \%)$, and therefore the relationship between waste fractions is

581 interpreted independently of waste datasets.

582 The variation array is divided into two triangles. The

583 upper triangle shows ratios or proportionalities between waste

584 fractions as pairwise log-ratio variances (variance $\ln \left(\mathrm{X}_{\mathrm{i}} / \mathrm{X}_{\mathrm{j}}\right)$

585 (see Eq. (12)). The lower triangle presents the pairwise log-

586 ratio means (Mean $\ln \left(\mathrm{X}_{\mathrm{j}} / \mathrm{X}_{\mathrm{i}}\right)$ (see Eq. (13)). Here, the

587 numerator is denoted by columns $\left(\mathrm{X}_{\mathrm{i}}\right)$, and denominator $\left(\mathrm{X}_{\mathrm{j}}\right)$ is

588 illustrated by rows. Moreover, the sign $(+$ or -$)$ of the log-ratio

589 mean values indicates the direction of the ratio between the 
relevant fractions.

594 Log-ratio variance values highlighted in grey (the value is 595 close to zero) indicate an almost constant ratio, whereas log-

596 ratio variance values in bold and highlighted in grey (usually

597 value is closed to zero) can be assumed to be zero, suggesting

598 an absolutely constant ratio (Pawlowsky-Glahn et al., 2015).

599 On the other hand, log-ratio variance values that are very much

600 higher than zero are highlighted in red, and these indicate no

601 relationship between the two relevant fractions, because their

602 ratios vary significantly.

603 For example, the mean log-ratio between plastic 604 packaging and paper and board was negative \{(mean $605(\log ($ Plastic/Paper $))=-1.4)\}$ (here, Plastic is $\mathrm{X}_{\mathrm{j}}$ from a row in

606 Table 6 and Paper is $\mathrm{X}_{\mathrm{i}}$ from a column in Table 6), indicating

607 that the households placed more mass of plastic packaging 608 than paper and board waste into their residual waste bins.

609 Furthermore, the variance in their log-ratio is small (0.77),

610 suggesting a strong relationship between these fractions. This

611 relationship has a negative ratio, which can be calculated as

612 follows:

613 plastic/paper $=\exp (-1.4)=0.25$

614 This result suggests that the ratio between discarded (1) plastic 
615 and (2) paper and board in residual household waste is constant

616 and estimated at 0.25 . This information could be used for

617 future developments in waste generation, i.e. to identify the

618 effects of new regulations and policies addressing packaging

619 materials.

620 The results shown in Table 6 indicate that the mean log-

621 ratio between avoidable animal-derived food waste and

622 unavoidable vegetable food waste was negative (-1.35).

623 However, the variance in their log-ratio was high (4.21),

624 thereby suggesting that the compositions of these fractions are

625 not proportional. In this case, the ratio between these fractions

626 is not constant.

627 Overall, the compositions of these pairs of waste fractions

628 are highly dependent: (1) unavoidable vegetable food waste

629 (UV) and paper (Paper), (2) paper (Paper) and plastic

630 packaging (Plastic) and (3) plastic packaging (Plastic) and

631 other waste fractions (Other). However, no relationship

632 between avoidable food waste fractions (AV and AA) and

633 material packaging (paper, plastic and metal) was identified.

634 For example, from the results in Table 7, it is apparent that the

635 ratio between avoidable animal-derived food waste and 636 packaging materials (plastic, paper and metal) is highly

637 variable (very high log-ratio variance painted in red).

638 Similarly, the ratio between avoidable vegetable food waste

639 and packaging materials (plastic, paper and metal) is not 
640 constant. These values indicate no constant ratios between

641 these fractions, signifying that there is no relationship between

642 these fractions based on the analysis of residual waste taken

643 from the 779 households.

644

\section{4. Discussion}

646 From the data in Table 3, arithmetic means of waste

647 fractions composition were influenced by the fact that the

648 assumption of normal distribution was violated (see Figure 4).

649 These results are consistent with previously published studies,

650 which concluded that the arithmetic mean is an inappropriate

651 means of estimating central values of compositional data

652 (Filzmoser et al., 2009; Pawlowsky-Glahn et al., 2015; van den

653 Boogaart et al., 2013). Consequently, any evaluation (e.g.

654 prevention, reduction or recycling of waste) or modelling (e.g.

655 life cycle assessment) based on the arithmetic mean of waste

656 fraction composition may lead to potentially wrong

657 conclusions, because they are based on erroneous estimates.

658 While the log transformation of waste composition may help

659 solve the problem of normality, its value is limited because it

660 relies on a univariate method, which ignores that the

661 compositions of waste fractions account for the limited data,

662 i.e. from 0 to 100 .

663 The results from the variation array were not in agreement

664 with those from the Pearson's correlation tests applied to both 
665 raw and log-transformed data. The correlation test applied to

666 waste fraction generation rates provided positive correlation

667 coefficients. On the other hand, negative correlation

668 coefficients were obtained when the correlation analysis was

669 applied to the composition of waste fractions in percentage

670 terms. The positive correlation coefficients were due to the size

671 of the mass effect of waste fractions ( $\mathrm{kg} /$ capita/week),

672 explaining why most waste fractions are positively and

673 significantly correlated with each other. The size effect of mass

674 was removed by calculating the correlation coefficient based

675 on the percentage composition of waste fractions. This then

676 generated negative correlation coefficients because of the

677 constant sum constraint (Aitchison, 1986; Pearson, 1897). As a

678 solution, the relationship between food waste fractions and

679 material packaging can be evaluated by the variation array

680 through a compositional data analysis technique. Log-ratio

681 coordinates remove the constant sum constraint and enable the

682 determination of the relationship between waste fractions,

683 independently of the unit. Another advantage of the variation

684 array is that the pairwise ratio between waste fractions could

685 be back-transformed to a desired unit and adequately

686 interpreted while preserving the structure of the original data

687 (Filzmoser and Hron, 2008; Pawlowsky-Glahn et al., 2015).

688 The advantage in this approach is that the variation array of

689 both waste datasets (percentage composition and mass per 
690 waste fraction per household) generates the same results

691 because of the log-ratio transformation.

692 Computing the arithmetic mean (mean-ilr), total variance

693 and variance array based on CoDa technique is a not

694 straightforward undertaking. However, numerous tools that do

695 not require advanced programming skills are freely available

696 (Templ et al., 2011; Thió-Henestrosa and Comas-Cufi, 2011;

697 van den Boogaart, 2008). Therefore, we urge practitioners and

698 researchers within solid waste management to address

699 adequately the constant sum constraint problem when

700 analysing solid waste composition data (Filzmoser et al.,

701 2009).

702

703 5. Conclusions

704 This study is a first attempt to address the problem

705 associated with the statistical analysis of waste fraction

706 composition data. Based on a systematic comparison of the

707 arithmetic mean and standard deviation applied to waste

708 fraction composition data, it was demonstrated that these

709 statistical parameters may generate erroneous and misleading

710 results when applied to fractional percentages (i.e. percentage

711 of paper, board, food waste, etc.). Moreover, correlation

712 coefficients based on raw or general transformation of data

713 depend strongly on the type of waste dataset. As a solution,

714 isometric log-ratio coordinates approximate the symmetrical 
715 distribution of data and remove the total constant sum

716 constraint, which restricts the application of classical statistics

717 to waste fraction composition. As a result, statistical analysis

718 applied to log-ratio coordinates generates consistent results

719 independently of the selected data type. The arithmetic means

720 of waste fractions, based on the isometric log-ratio, summed

721 up to 100 . The variation array provides a ratio between waste

722 fractions and offers consistent conclusions regardless of the

723 data type.

724

725 Acknowledgments

726 The authors acknowledge the Danish Strategic Research

727 Council for financing this study via the IRMAR (Integrated

728 Resource Management \& Recovery) Project (No. 11-116775).

729 We wish to thank Compositional Data Analysis and Related

730 methods (CoDa- RETOS) for their support through the project

731 MINISTERIO ECONOMÍA Y COMPETIVIDAD (Ref:

732 MTM2015-65016-C2-1-R (MINECO/FEDER, UE). The

733 Danish Environmental Protection Agency (EPA) and Claus

734 Petersen from ECONET AS are also acknowledged for their

735 valuable support and contributions.

736

\section{References}

738 Aitchison, J., 1994. A Concise Guide to Compositional Data 
Aitchison, J., 1986. The Statistical Analysis of Compositional Data. Monographs on Statistics and Applied Probability. Chapman \& Hall Ltd., London (UK).Reprinted (2003)

with additional material by The Blackburn Press, Caldwell, NJ.

Alter, H., 1989. The Origins of Municipal Solid Waste: the Relations Between Residues From Packaging Materials and Food. Waste Management 7, 103-114. doi:10.1177/0734242X8900700115.

Buccianti, A., Pawlowsky-Glahn, V., 2011. Compositional Data Analysis, Compositional Data Analysis: Theory and Applications. John Wiley \& Sons, Ltd, Chichester, UK. doi:10.1002/9781119976462.

Chang, N.-B., Davila, E., 2008. Municipal solid waste characterizations and management strategies for the Lower Rio Grande Valley, Texas. Waste Management 28, 77694. doi:10.1016/j.wasman.2007.04.002.

Christensen, T.H., 2011. Introduction to Waste Management. in Solid Waste Technology and Management 3-16, in: Christensen, T.H. (Ed.), Solid Waste Technology \& Management, Volume $1 \& 2$. Chichester, UK. doi:10.1002/9780470666883.ch1.

Ciroth, A., Muller, S., Weidema, B., Lesage, P., 2013. Empirically based uncertainty factors for the pedigree matrix in ecoinvent. International Journalof Life Cycle Assessment 1-11. doi:10.1007/s11367-013-0670-5.

Dahlén, L., Vukicevic, S., Meijer, J.-E., Lagerkvist, A., 2007. Comparison of different collection systems for sorted household waste in Sweden. Waste Management 27, 1298-305. doi:10.1016/j.wasman.2006.06.016.

Edjabou, M.E., Boldrin, A., Scheutz, C., Astrup, T.F., 2015. Source segregation of food waste in office areas: Factors affecting waste generation rates and quality. Waste Management 46, 94-102. doi:10.1016/j.wasman.2015.07.013.

Edjabou, M.E., Petersen, C., Scheutz, C., Astrup, T.F., 2016. Food waste generation and composition in Danish households. Waste Management 52, 256-268. doi:10.1007/s13398-014-0173-7.2.

Egozcue, J.J., Pawlowsky Glahn, V., Mateu-Figueras, G., Barceló Vidal, C., 2003. Isometric logratio for compositional data analysis. Mathematical Geosciences 35, 279-300. doi:10.1023/A:1023818214614.

Page 32 of 35 
800

801

802

803

804

805

806

807

808

809

810

811

812

813

814

815

816

817

818

819

820

821

822

823

824

825

European Commission, 2004. Methodology for the Analysis of Solid Waste (SWA-tool). User Version 43, 1-57.

Filzmoser, P., Hron, K., 2008. Correlation Analysis for Compositional Data. Mathematical Geosciences. 41, 905919. doi:10.1007/s11004-008-9196-y.

Filzmoser, P., Hron, K., Reimann, C., 2009. Univariate statistical analysis of environmental (compositional) data: Problems and possibilities. Science of the Total Environment407, 6100-6108. doi:10.1016/j.scitotenv.2009.08.008.

Peter Filzmoser (2015). StatDA: Statistical Analysis for Environmental Data. R package version 1.6.9. https://CRAN.R-project.org/package=StatDA.

Hanc, A., Novak, P., Dvorak, M., Habart, J., Svehla, P., 2011. Composition and parameters of household bio-waste in four seasons. Waste Management 31, 1450-60. doi:10.1016/j.wasman.2011.02.016.

Härdle, W., Simar, L., 2015. Applied Multivariate Statistical Analysis Applied Multivariate Statistical Analysis, Technometrics. doi:10.1198/tech.2005.s319

Lagerkvist, A., Ecke, H., Christensen, T.H., 2011. Waste Generation and Characterization Waste Characterization : Approaches and Methods, in: Christensen, T.H. (Ed.), Solid Waste Technology \& Management, Volume $1 \& 2$. Chichester, UK. doi:10.1002/9780470666883.ch5.

Milke, M.W., Wong, V., McBean, E. a., 2008. Describing variability of MSW composition data with the log-logistic distribution. Waste ManagementRes. 26, 355-361. doi:10.1177/0734242X08089464.

Naveen, B.P., Mahapatra, D.M., Sitharam, T.G., Sivapullaiah, P.V., Ramachandra, T.V., 2016. Physico-chemical and biological characterization of urban municipal landfill leachate. Environ. Pollut. doi:10.1016/j.envpol.2016.09.002.

Palarea-Albaladejo, J., Martín-Fernández, J.A., 2015. ZCompositions - $\mathrm{R}$ package for multivariate imputation of left-censored data under a compositional approach. Chemometrics and Intelligent Laboratory Systems. 143, 85-96. doi:10.1016/j.chemolab.2015.02.019.

Pawlowsky-Glahn, V., Egozcue, J., Tolosana-Delgado, R., 2015. Modeling and Analysis of Compositional Data. John Wiley \& Sons.

Pawlowsky, G. V, Egozcue, J., Delgado, R.T., 2008. Lecture 
notes on compositional data analysis 1-100.

Pearson, K., 1897. Mathematical Contributions to the Theory of Evolution. - On a Form of Spurious Correlation Which May Arise When Indices Are Used in the Measurement of Organs. Proc. R. Soc. London 60, 489-498. doi:10.1098/rspl.1896.0076.

R Core Team, 2017. R: A Language and Environment for Statistical Computing.

Reimann, C., Filzmoser, P., Garrett, R.G., Dutter, R., 2008. Statistical Data Analysis Explained: Applied Environmental Statistics With R, Statistical Data Analysis Explained: Applied Environmental Statistics With R. John Wiley \& Sons, Ltd, Chichester, UK. doi:10.1002/9780470987605.

Templ, M., Hron, K., Filzmoser, P., 2011. robCompositions: an R-package for robust statistical analysis of compositional data, in: Pawlowsky-Glahn, V., Buccianti, A. (Eds.), Compositional Data Analysis. Theory and Applications. John Wiley \& Sons, Chichester (UK), pp. 341-355.

Thió-Henestrosa, S., Comas-Cufi, M., 2011. CoDaPack v2 USER's GUIDE.

USEPA, 2006. Data Quality Assessment: Statistical Methods for Practitioners, U.S. Envir. ed. U.S. Environmental Protection Agency, Washigton, D.C.

van den Boogaart, K.G., 2008. "compositions": A unified R package to analyze compositional data. Comput. Geosci. 34, 320-338.

van den Boogaart, K.G., Tolosana-Delgado, R., Boogaart, K.G. Van Den, Tolosana-Delgado, R., 2013. Analyzing Compositional Data with R. Springer Berlin Heidelberg, Berlin, Heidelberg. doi:10.1007/978-3-642-36809-7.

Wilcox, R., 2012. Introduction to Robust Estimation and Hypothesis Testing, Introduction to Robust Estimation and Hypothesis Testing. Elsevier. doi:10.1016/B978-0-12386983-8.00008-1.

Williams, H., Wikström, F., Otterbring, T., Löfgren, M., Gustafsson, A., 2012. Reasons for household food waste with special attention to packaging. Journal of Cleaner Production. 24, 141-148. doi:10.1016/j.jclepro.2011.11.044.

Xu, C., Gertner, G.Z., 2008. Uncertainty and sensitivity analysis for models with correlated parameters. Reliability Engineering and System Safety 93, 1563-1573. 
doi:10.1016/j.ress.2007.06.003.

870

Page $\mathbf{3 5}$ of $\mathbf{3 5}$ 
Table 1: List of residual waste fractions and components included

\begin{tabular}{|c|c|}
\hline Waste fractions & Components \\
\hline \multirow{2}{*}{ Avoidable vegetable food waste $\left(\mathrm{AV}^{1}\right)$} & Cooked food (e.g. rice, pasta, potatoes, etc.) \\
\hline & Fresh fruit, fresh carrots and potatoes, bread, cereals \\
\hline \multirow[t]{2}{*}{ Avoidable animal-derived food waste $\left(\mathrm{AA}^{1}\right)$} & Cooked eggs, rest of food containing meat, fish, etc. \\
\hline & Canned meat and fish, \\
\hline \multirow[t]{2}{*}{ Unavoidable vegetable food waste $\left(\mathrm{UV}^{1}\right)$} & Residues from fruits, vegetables, coffee grounds \\
\hline & Eggs not cooked, dairy products, not cooked meat and fish, etc. \\
\hline \multirow[t]{2}{*}{ Unavoidable animal-derived food waste $\left(\mathrm{UA}^{1}\right)$} & Leftovers containing meat, fish, skins and bones, etc. \\
\hline & $\begin{array}{l}\text { Cheese rinds, eggs shells, other non-edible mixed animal and } \\
\text { vegetable products }\end{array}$ \\
\hline \multirow[t]{3}{*}{ Paper and board (Paper:Pa $\left.{ }^{1}\right)$} & $\begin{array}{l}\text { Advertisements , Books \& booklets, Magazines \& Journals, } \\
\text { Newspapers }\end{array}$ \\
\hline & Office paper, Phonebooks, Miscellaneous paper, Corrugated boxes \\
\hline & Beverage cartons, Folding boxes, Miscellaneous board \\
\hline Plastic packaging (Plastic: $\mathrm{Pl}^{1}$ ) & $\begin{array}{l}\text { Packaging plastics, such as PET/PETE, HDPE, PVC/V, } \\
\text { LDPE/LLDPE, PP, PS, others, etc }\end{array}$ \\
\hline \multirow[t]{2}{*}{ Metal packaging (Metal;Me $\left.{ }^{1}\right)$} & Metal packaging containers (ferrous and non-ferrous) \\
\hline & Composites \\
\hline \multirow[t]{4}{*}{ Others $\left(\mathrm{Ot}^{1}\right)$} & Gardening waste, glass packaging, other/special glass, \\
\hline & Table and kitchen ware glass, Non-packaging metals \\
\hline & Non-packaging plastic, plastic film \\
\hline & $\begin{array}{l}\text { Miscellaneous combustible waste, inert (other non-combustible), } \\
\text { special waste }\end{array}$ \\
\hline
\end{tabular}

${ }^{1}$ Refers to abbreviation of waste fractions in equations and

figures and other tables in the present paper

Table 2: Signs code of the sequential binary partition applied to the residual household waste fractions: Balance code, $(+1)$ means that the fraction is assigned to the first group (numerator), (-1) to the second group, and 0 the fraction is not included in the partition in this balance

\begin{tabular}{ccccccccc}
\hline \multirow{2}{*}{ Coordinates } & \multicolumn{7}{c}{ Residual household waste fractions } \\
\cline { 2 - 8 } & $\mathrm{AV}^{\mathrm{a}}$ & $\mathrm{UV}^{\mathrm{b}}$ & $\mathrm{AA}^{\mathrm{c}}$ & $\mathrm{UA}^{\mathrm{d}}$ & Paper $^{\mathrm{e}}$ & Metal $^{\mathrm{f}}$ & Plastic $^{\mathrm{g}}$ & Other $^{\mathrm{h}}$ \\
\hline $\mathrm{ilr}$ & +1 & +1 & +1 & +1 & -1 & -1 & -1 & -1 \\
$\mathrm{Il}$ & +1 & +1 & -1 & -1 & 0 & 0 & 0 & 0 \\
$\mathrm{Ilr}_{3}$ & +1 & -1 & 0 & 0 & 0 & 0 & 0 & 0 \\
$\mathrm{Ilr}_{4}$ & 0 & 0 & +1 & -1 & 0 & 0 & 0 & 0 \\
$\mathrm{Ilr}_{5}$ & 0 & 0 & 0 & 0 & +1 & +1 & -1 & -1 \\
$\mathrm{Ilr}_{6}$ & 0 & 0 & 0 & 0 & +1 & -1 & 0 & 0 \\
$\mathrm{Ilr}_{7}$ & 0 & 0 & 0 & 0 & 0 & 0 & +1 & -1 \\
\hline
\end{tabular}

${ }^{a}$ Avoidable vegetable food waste

${ }^{b}$ Unavoidable vegetable food waste

${ }^{c}$ Avoidable animal-derived food waste

${ }^{d}$ Unavoidable animal-derived food waste

${ }^{e}$ Paper and board; ${ }^{f}$ Metal packagin.; ${ }^{g}$ Plastic packaging; ${ }^{h}$ grouped waste fraction (see Table 1 for waste fractions) 
37 Table 3: Comparison of arithmetic means computed based on

38 raw data (Mean), log transformed data (Log-Mean), back-

39 transformed data (Mean-log) and back-transformed isometric

40 log-ratio mean (Mean-ilr)

\begin{tabular}{|c|c|c|c|c|c|}
\hline \multirow[t]{2}{*}{ Waste fractions } & \multicolumn{4}{|c|}{ Classical statistics } & \multirow{2}{*}{$\begin{array}{c}\text { CoDa-technique } \\
\text { Mean-ilr }^{\mathrm{d}}\end{array}$} \\
\hline & Mean $^{\mathrm{a}}$ & Log-mean ${ }^{b}$ & Mean- $\log ^{\mathrm{c}}$ & Median & \\
\hline Avoidable vegetable food waste & 15.57 & 2.32 & 10.14 & 13.84 & 13.3 \\
\hline Unavoidable vegetable food waste & 17.03 & 2.47 & 11.87 & 15.22 & 15.5 \\
\hline Avoidable animal-derived food waste & 6.98 & 1.13 & 3.09 & 5.11 & 4.0 \\
\hline Unavoidable animal-derived food waste & 2.21 & -0.06 & 0.94 & 1.08 & 1.2 \\
\hline Paper and board & 20.79 & 2.91 & 18.28 & 18.52 & 23.9 \\
\hline Metal packaging & 2.12 & 0.09 & 1.09 & 1.44 & 1.4 \\
\hline Plastic packaging & 5.51 & 1.50 & 4.49 & 4.76 & 5.9 \\
\hline Other & 29.80 & 3.28 & 26.59 & 26.30 & 34.8 \\
\hline Total & 100.00 & 13.63 & 76.49 & 86.27 & 100.0 \\
\hline Wet waste kg per household per week & 10.41 & & 8.80 & 9.52 & \\
\hline Wet waste $\mathrm{kg}$ per person per week & 4.00 & & 3.45 & 3.42 & \\
\hline
\end{tabular}

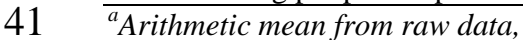

$42{ }^{b}$ Arithmetic mean for log-transformed data;

$43{ }^{c}$ Arithmetic mean based on back-transformation of the log-transformed data;

$44{ }^{d}$ Arithmetic mean for ilr coordinates, which is back-transformed

Table 4 Comparison of standard deviation values based on

48 waste fraction compositions data set (SD) and variance (\%

49 Var); log-transformed (SD-log) and variance of log-

50 transformed (\% Var-log) absolute contribution of each waste

51 fractions (SD-clr) to total variance, and the percentage

52 distribution of the total variance (SD-clr) $(n=779)$

\begin{tabular}{lcccccc}
\hline Waste fractions & \multicolumn{3}{c}{ Classical statistics } & \multicolumn{3}{c}{ CoDa-technique } \\
\hline & SD & \%Var & SD-log & \%Var-log & SD-clr & \%Var-clr \\
Avoidablevegetablefoodwaste & 10.76 & 17.52 & 3.49 & 12.55 & 1.1 & 13.16 \\
Unavoidablevegetablefoodwaste & 11.51 & 20.05 & 2.99 & 9.21 & 1.03 & 11.56 \\
Avoidableanimal-derivedfoodwaste & 6.88 & 7.16 & 5.68 & 33.24 & 1.51 & 24.73 \\
Unavoidableanimal-derivedfoodwaste & 3.12 & 1.47 & 4.46 & 20.5 & 1.32 & 18.84 \\
Paperandboard & 10.9 & 17.98 & 1.68 & 2.91 & 0.7 & 5.27 \\
Metalpackaging & 3.29 & 1.64 & 3.76 & 14.57 & 1.17 & 14.81 \\
Plasticpackaging & 4.26 & 2.75 & 2.04 & 4.29 & 0.72 & 5.53 \\
Other & 14.41 & 31.43 & 1.63 & 2.74 & 0.75 & 6.09 \\
Totalvariance(totvar) & 660.76 & 100.00 & 97.05 & 100.00 & 9.23 & 100.00 \\
\hline
\end{tabular}

53 
Table 5 Correlation matrix from Pearson correlation test and significance levels of raw data shown in Figure 2 (r: range:-

$56 \quad 1.00$ to +1.00$)$

\begin{tabular}{|c|c|c|c|c|c|c|c|c|c|}
\hline Waste fractions & $A V^{d}$ & $\mathrm{UV}^{\mathrm{e}}$ & $\mathrm{AA}^{\mathrm{f}}$ & $\mathrm{UA}^{\mathrm{g}}$ & Paper $^{\mathrm{h}}$ & Metal $^{\text {i }}$ & Plastic $^{j}$ & Other & Datasets \\
\hline \multirow{2}{*}{$\begin{array}{l}\text { Avoidable vegetable food waste } \\
\text { (AV) }\end{array}$} & 1.00 & $* * *$ & $* * *$ & $* * *$ & **** & & **** & $* * *$ & Percentage $\%$ \\
\hline & 1.00 & $* * *$ & $* * *$ & $* *$ & $* * *$ & & $* * *$ & $* * *$ & $\mathrm{~kg} /$ capita/week \\
\hline \multirow{2}{*}{$\begin{array}{l}\text { Unavoidable vegetable food waste } \\
\text { (UV) }\end{array}$} & -0.17 & 1.00 & $* * *$ & 0.00 & $* * *$ & $*$ & $* *$ & $* * *$ & Percentage $\%$ \\
\hline & 0.23 & 1.00 & $* * *$ & $* * *$ & $* * *$ & $*$ & $*$ & $* * *$ & $\mathrm{~kg}$ /capita/week \\
\hline \multirow{2}{*}{$\begin{array}{l}\text { Avoidable animal-derived food waste } \\
\text { (AA) }\end{array}$} & 0.16 & -0.19 & 1.00 & 0.00 & $* * *$ & 0.00 & 0.00 & $* * *$ & Percentage $\%$ \\
\hline & 0.46 & 0.14 & 1.00 & $* * *$ & $* * *$ & 0.00 & $* *$ & $* * *$ & kg/capita/week \\
\hline \multirow{2}{*}{$\begin{array}{l}\text { Unavoidable animal-derived food } \\
\text { Waste (UA) }\end{array}$} & -0.12 & 0.02 & 0.00 & 1.00 & . & 0.00 & 0.00 & $* *$ & Percentage $\%$ \\
\hline & 0.11 & 0.17 & 0.14 & 1.00 & $*$ & $*$ & . & $*$ & kg/capita/week \\
\hline \multirow{2}{*}{ Paper and board } & -0.30 & -0.16 & -0.21 & -0.06 & 1.00 & $*$ & 0.00 & $* * *$ & Percentage $\%$ \\
\hline & 0.29 & 0.19 & 0.18 & 0.07 & 1.00 & 0.00 & $* *$ & $* * *$ & kg/capita/week \\
\hline \multirow{2}{*}{ Metal packaging } & -0.07 & -0.08 & -0.03 & 0.03 & -0.09 & 1.00 & 0.00 & 0.00 & Percentage $\%$ \\
\hline & 0.07 & 0.08 & 0.04 & 0.07 & 0.04 & 1.00 & 0.00 & $* * *$ & $\mathrm{~kg} /$ capita/week \\
\hline \multirow{2}{*}{ Plastic packaging } & -0.13 & -0.10 & -0.05 & 0.03 & -0.04 & 0.05 & 1.00 & $*$ & Percentage $\%$ \\
\hline & 0.13 & 0.09 & 0.10 & 0.06 & 0.11 & 0.04 & 1.00 & $* * *$ & kg/capita/week \\
\hline \multirow{2}{*}{ Other } & -0.38 & -0.41 & -0.27 & -0.10 & -0.26 & -0.06 & -0.08 & 1.00 & Percentage $\%$ \\
\hline & 0.30 & 0.15 & 0.21 & 0.07 & 0.28 & 0.14 & 0.14 & 1.00 & kg/capita/week \\
\hline
\end{tabular}

${ }^{* * * *}$ Very high significance probability higher than 0.001

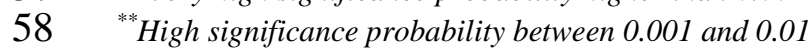

59 * Significance probability between 0.01 and 0.05

$60 \quad 0.00$ no significance-probability higher than 0.05

61 amount of waste (wet basis) per household per week

$62{ }^{b}$ amount of waste (wet basis) per person per week

$63{ }^{c}$ Composition of residual household waste on wet basis.

$64{ }^{d}$ Avoidable vegetable food waste

$65{ }^{e}$ Unavoidable vegetable food waste

$66{ }^{f}$ Avoidable animal-derived food waste

$67{ }^{g}$ Unavoidable animal-derived food waste

$68{ }^{h}$ Paper; ${ }^{i}$ Metal packaging.; ${ }^{j}$ Plastic packaging, ${ }^{k}$ Other (see Table 1).

69 Table 6: Variation array of waste fraction compositions

70 computed using log-ratio transformation of the waste dataset

71 shown in Figure 2

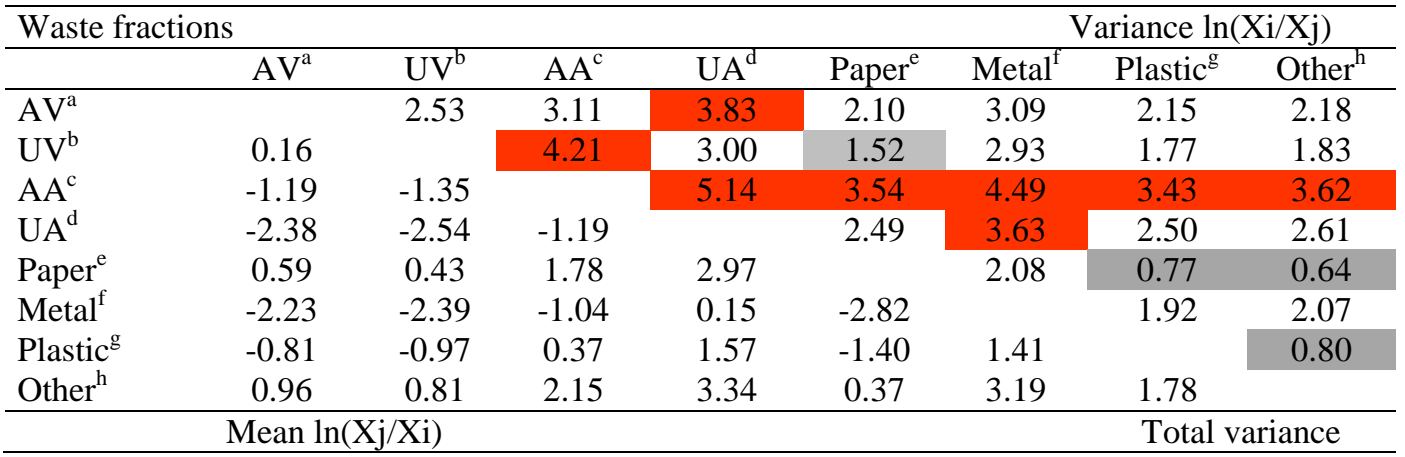

72

${ }^{a}$ Avoidable vegetable food waste

$73{ }^{b}$ Unavoidable vegetable food waste

$74{ }^{c}$ Avoidable animal-derived food waste

$75{ }^{d}$ Unavoidable animal-derived food waste

76 e Paper and board; ${ }^{\circ}$ Metal packagin.;

77 Plastic packaging;

$78{ }^{h}$ grouped waste fraction (see Table 1 for waste fractions) 

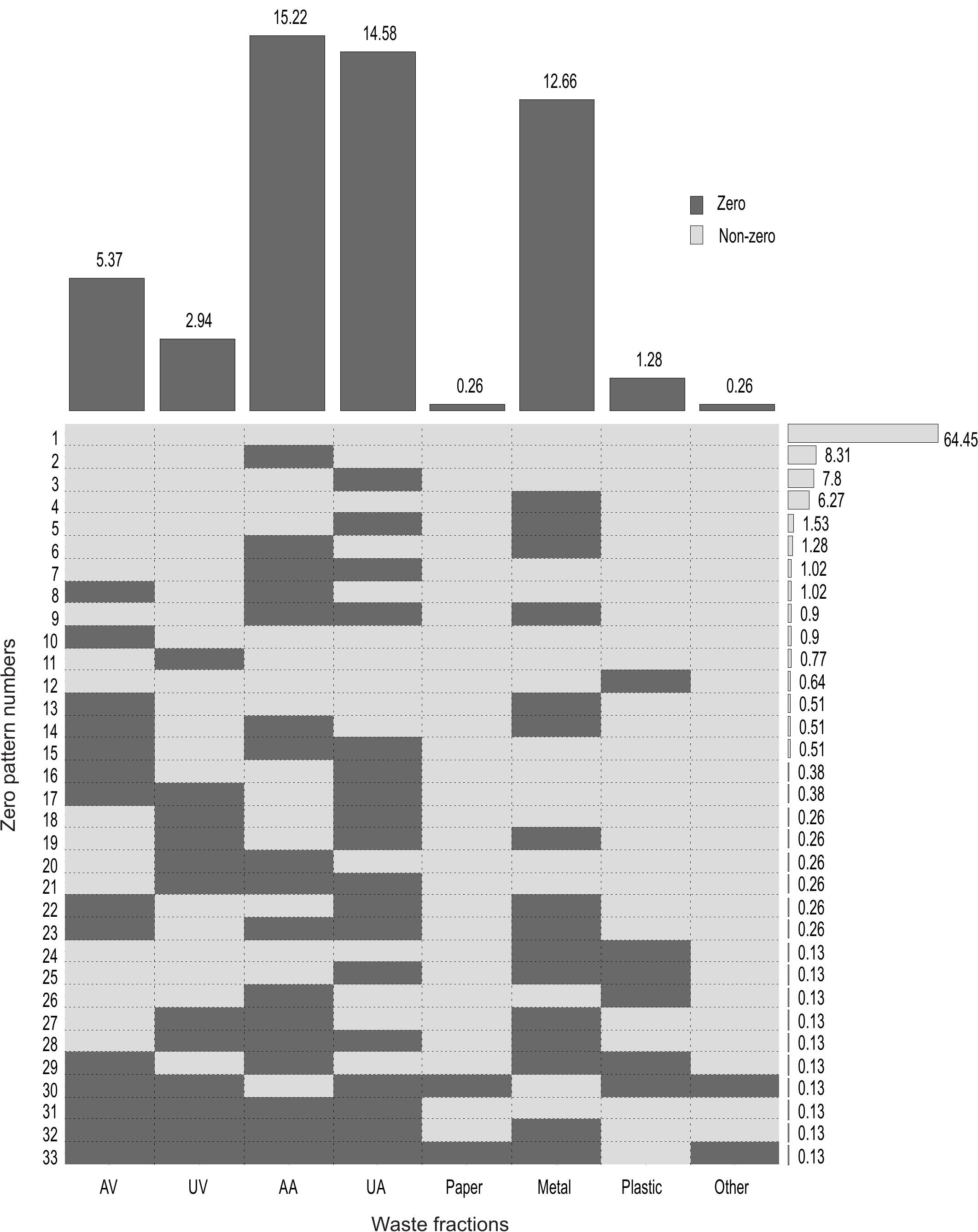
Figure 3
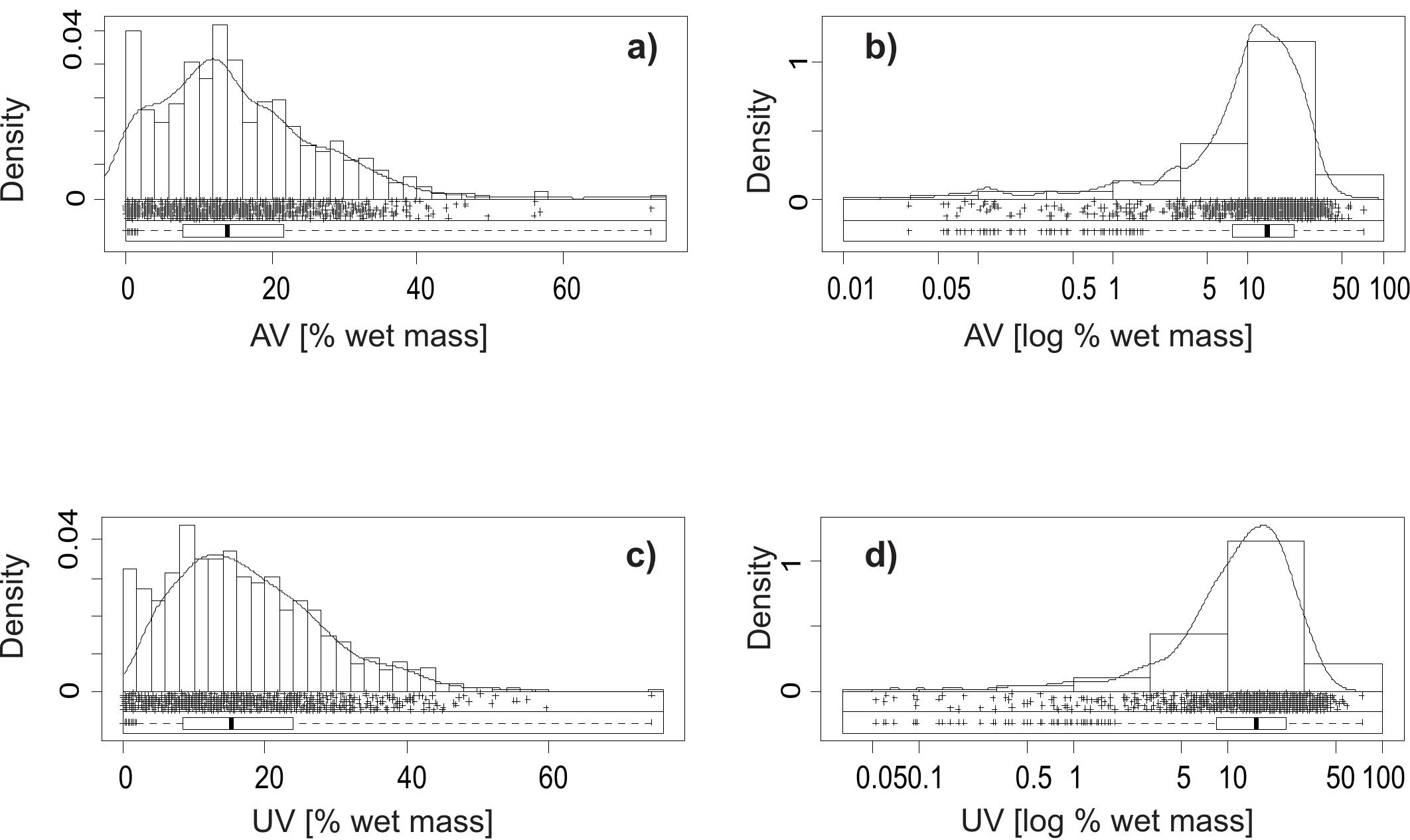
Figure 4

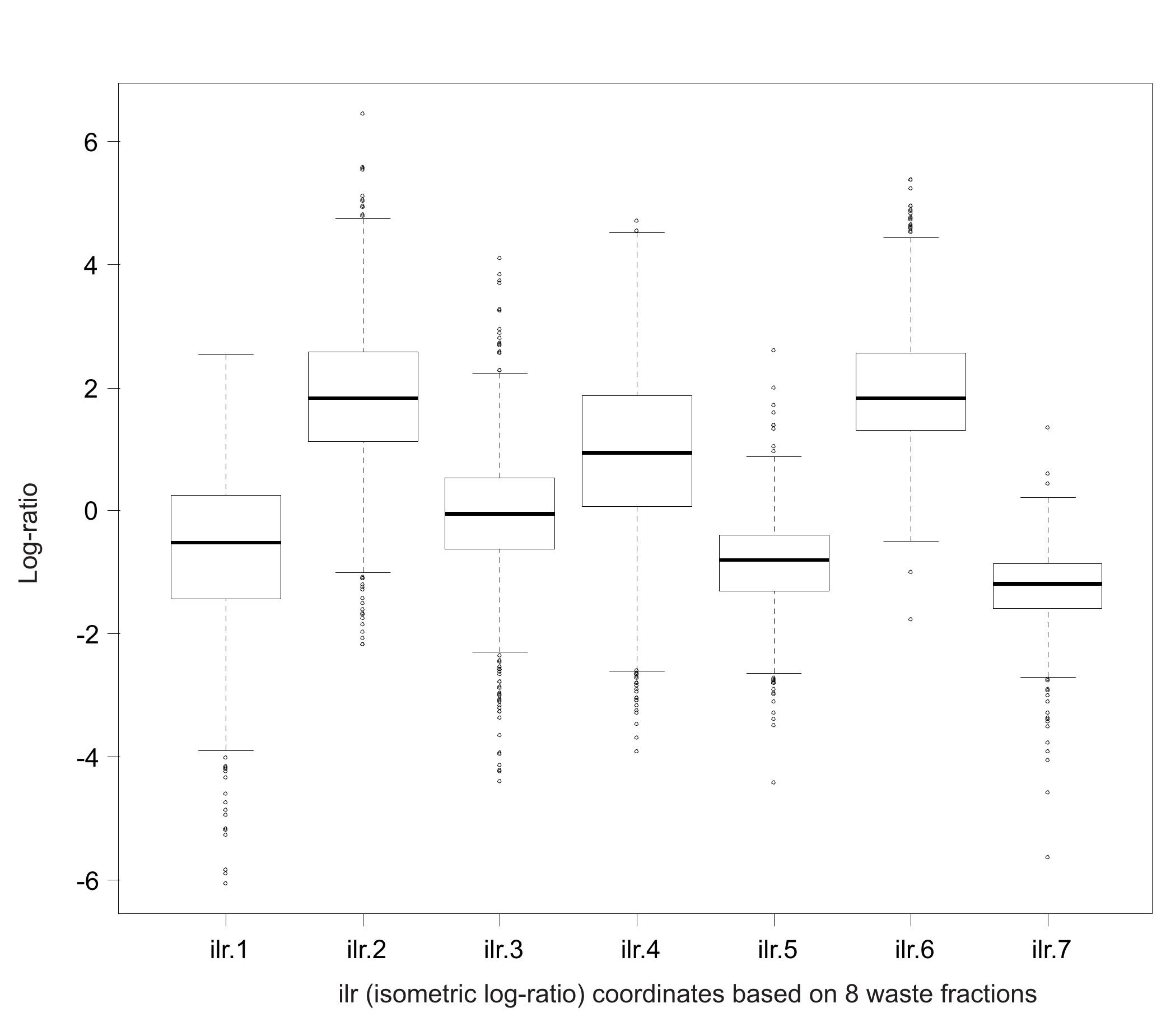

\section{Figure 4}

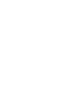

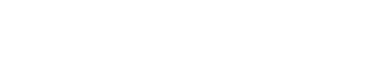

$\sqrt{2}+x^{2}$

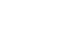

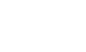

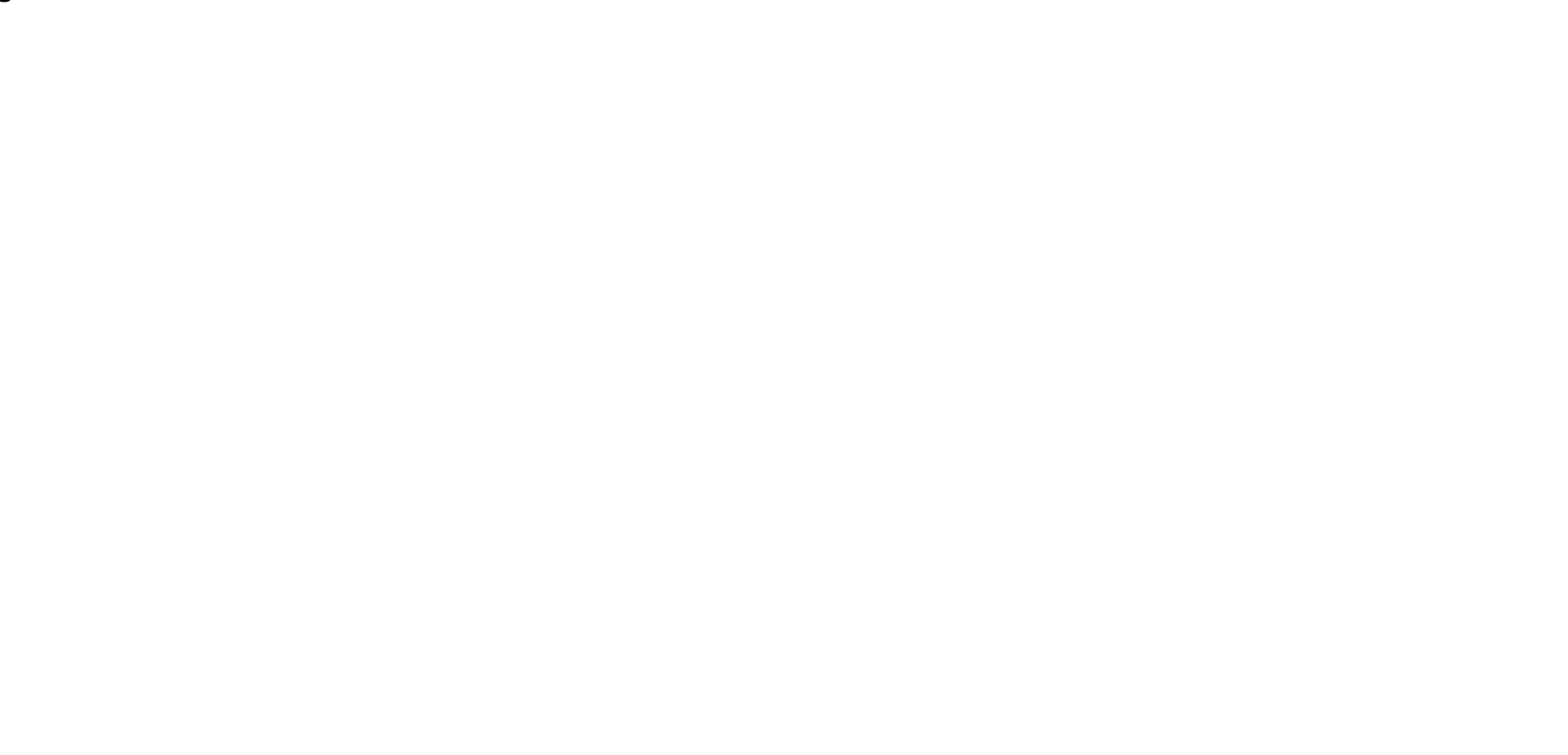

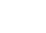

$x^{2}$ 
Figure 5

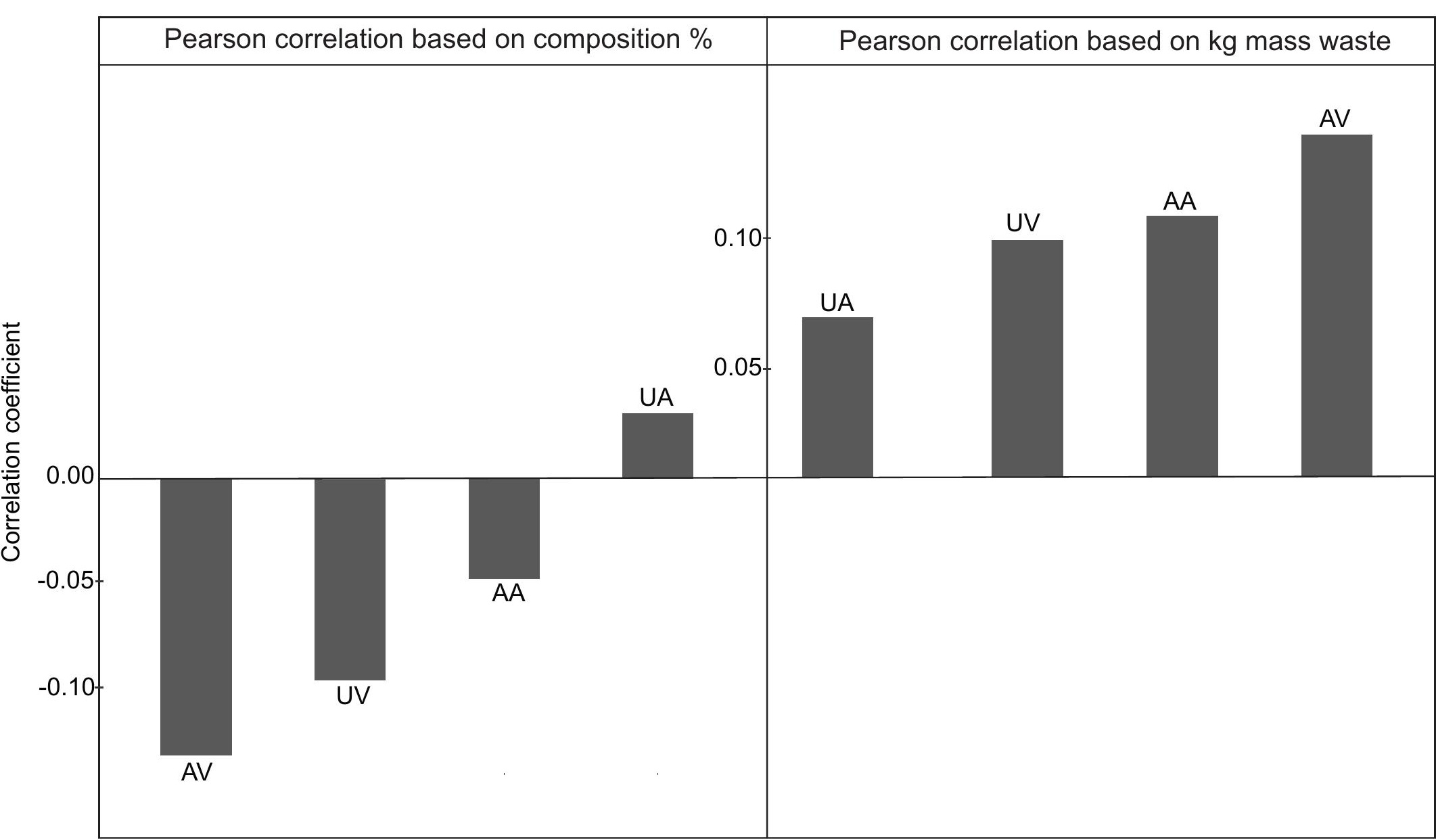


18 Figure capitations

19

20

Figure 1: Identification of zero value patterns in residual household waste dataset subdivided into eight waste fractions (see Table 1) and consisting of 779 observations (households). Vertical bars (in dark grey) represent percentage of count number of zero values for each waste fractions; Horizontal bars (light grey) indicate the percentage of count number of no zero value for each combination of eight waste fractions in the households-33 zero values patterns were observed.

Figure 2: Percentage distribution of the composition of residual household waste fractions on wet mass basis (see Table 1 for abbreviation).

Figure 3: Combined histogram and boxplot of raw (a) and logtransformed (b) avoidable vegetable food waste; and raw (c) and log-transformed (d) unavoidable vegetable food waste.

Figure 4: Boxplot showing the distribution of ilr coordinates (number of coordinates equals to number of waste fractions $(D=8)$ minus 1$)$

Figure 5: Results of Pearson correlation test between plastic packaging and food waste fractions (AV, UV, AA, and UA), based on (i) percentage (\%) and (ii) $\mathrm{kg}$ mass of waste fractions. 
Statistical analysis of solid waste composition data: arithmetic mean, standard deviation and correlation coefficients

Maklawe Essonanawe Edjabou ${ }^{1 *}$, Josep Antoni Martín-Fernández ${ }^{2}$, Charlotte Scheutz ${ }^{1}$, Thomas Fruergaard Astrup ${ }^{1}$

1) Department of Environmental Engineering, Technical University of Denmark, $2800 \mathrm{Kgs}$.

Lyngby, Denmark

2) Dept. Computer Science, Applied Mathematics and Statistics, University of Girona, Campus Montilivi (P4), E-17071 Girona, Spain 


\section{Supplementary materials (SM)}

Supplementary materials contain detailed food waste data used for calculations. SMs are divided into tables (Table SM) and figures (Figure SM). 


\section{Supplementary materials (SM) -Tables}

SM Table 1 Correlation matrix from Pearson`correlation test and significance levels of logtransformed data(r: range:-1.00 to +1.00)

\begin{tabular}{|c|c|c|c|c|c|c|c|c|c|}
\hline & $\mathrm{AV}^{\mathrm{d}}$ & $\mathrm{UV}^{\mathrm{e}}$ & $\mathrm{AA}^{\mathrm{f}}$ & $\mathrm{UA}^{\mathrm{g}}$ & Paper $^{\mathrm{h}}$ & Metal $^{\mathrm{i}}$ & Plastic $^{j}$ & Other & Datasets \\
\hline \multirow{2}{*}{$\begin{array}{l}\text { Avoidable vegetable food waste } \\
\text { (AV) }\end{array}$} & 1 & $*$ & $* * *$ & 0 & $* * *$ & & 0 & $* * *$ & \multirow{2}{*}{$\begin{array}{l}\text { Percentage } \% \\
\mathrm{~kg} / \text { capita/week }\end{array}$} \\
\hline & 1 & $* * *$ & $* * *$ & $* * *$ & $* * *$ & $* * *$ & $* * *$ & $* * *$ & \\
\hline \multirow{2}{*}{$\begin{array}{l}\text { Unavoidable vegetable food waste } \\
\text { (UV) }\end{array}$} & 0.08 & 1 & 0 & $* * *$ & 0 & 0 & 0 & *** & \multirow{2}{*}{$\begin{array}{l}\text { Percentage } \% \\
\text { kg/capita/week }\end{array}$} \\
\hline & 0.41 & 1 & $* * *$ & $* * *$ & $* * *$ & $* * *$ & $* * *$ & $* * *$ & \\
\hline \multirow{2}{*}{$\begin{array}{l}\text { Avoidable animal-derived food } \\
\text { waste (AA) }\end{array}$} & 0.34 & 0 & 1 & 0 & $* * *$ & & 0 & $* * *$ & \multirow{2}{*}{$\begin{array}{l}\text { Percentage } \% \\
\mathrm{~kg} / \text { capita/week }\end{array}$} \\
\hline & 0.53 & 0.27 & 1 & $* * *$ & $* * *$ & $* * *$ & $* * *$ & $* * *$ & \\
\hline \multirow{2}{*}{$\begin{array}{l}\text { Unavoidable animal-derived food } \\
\text { Waste (UA) }\end{array}$} & -0.01 & 0.13 & 0.02 & 1 & 0 & $*$ & $* *$ & $* *$ & \multirow{2}{*}{$\begin{array}{l}\text { Percentage } \% \\
\text { kg/capita/week }\end{array}$} \\
\hline & 0.23 & 0.29 & 0.2 & 1 & $* * *$ & $* * *$ & $* * *$ & $* * *$ & \\
\hline \multirow{2}{*}{ Paper and board } & -0.21 & -0.05 & -0.14 & 0.01 & 1 & 0 & 0 & $* * *$ & \multirow{2}{*}{$\begin{array}{l}\text { Percentage } \% \\
\mathrm{~kg} / \text { capita/week }\end{array}$} \\
\hline & 0.41 & 0.38 & 0.31 & 0.22 & 1 & $* * *$ & $* * *$ & $* * *$ & \\
\hline \multirow{2}{*}{ Metal packaging } & 0.07 & 0.01 & 0.06 & 0.09 & -0.05 & 1 & $* * *$ & & \multirow{2}{*}{$\begin{array}{l}\text { Percentage \% } \\
\mathrm{kg} / \text { capita/week }\end{array}$} \\
\hline & 0.34 & 0.24 & 0.27 & 0.21 & 0.28 & 1 & $* * *$ & $* * *$ & \\
\hline \multirow{2}{*}{ Plastic packaging } & -0.04 & -0.04 & 0.04 & 0.11 & 0.02 & 0.18 & 1 & $*$ & \multirow{2}{*}{$\begin{array}{l}\text { Percentage } \% \\
\text { kg/capita/week }\end{array}$} \\
\hline & 0.4 & 0.29 & 0.36 & 0.25 & 0.38 & 0.38 & 1 & $* * *$ & \\
\hline \multirow{2}{*}{ Other } & -0.31 & -0.37 & -0.22 & -0.1 & -0.27 & -0.06 & -0.08 & 1 & \multirow{2}{*}{$\begin{array}{l}\text { Percentage } \% \\
\mathrm{~kg} / \text { capita/week }\end{array}$} \\
\hline & 0.38 & 0.23 & 0.29 & 0.18 & 0.43 & 0.3 & 0.38 & 1 & \\
\hline
\end{tabular}

${ }^{* * * *}$ Very high significance probability higher than 0.001

${ }^{* *}$ High significance probability between 0.001 and 0.01

*Significance probability between 0.01 and 0.05

() no significance-probability higher than 0.05

${ }^{a}$ amount of waste (wet basis) per household per week

${ }^{b}$ amount of waste (wet basis) per person per week

${ }^{c}$ Composition of residual household waste on wet basis.

${ }^{d}$ Avoidable vegetable food waste

${ }^{e}$ Unavoidable vegetable food waste

${ }^{f}$ Avoidable animal-derived food waste

${ }^{g}$ Unavoidable animal-derived food waste

${ }^{h}$ Paper; ${ }^{i}$ Metal packaging.; ${ }^{j}$ Plastic packaging; ${ }^{k}$ Other (see Table 1 ).

SM Table 2 Summary of waste fraction generation rates data set before zero values replacement

\begin{tabular}{lcccc}
\hline & $\min$ & $\max$ & mean & Standard deviation \\
\hline Avoidable vegetable food waste (AV) & 0.000 & 12.435 & 1.760 & 1.654 \\
Unavoidable vegetable food waste (UV) & 0.000 & 21.750 & 1.687 & 1.457 \\
Avoidable animal-derived food waste (AA) & 0.000 & 9.314 & 0.755 & 0.891 \\
Unavoidable animal-derived food Waste (UA) & 0.000 & 5.450 & 0.210 & 0.344 \\
Paper and board & 0.050 & 14.519 & 2.042 & 1.616 \\
Metal packaging & 0.000 & 13.415 & 0.213 & 0.556 \\
Plastic packaging & 0.000 & 19.415 & 0.524 & 0.753 \\
Other & 0.194 & 25.747 & 3.063 & 2.583 \\
\hline
\end{tabular}

SM Table 3 Summary of waste fraction generation rates data set after zero values replacement

\begin{tabular}{lcccc}
\hline & $\min$ & $\max$ & $\operatorname{mean}$ & Standard deviation \\
\hline Avoidable vegetable food waste (AV) & 0.006 & 12.435 & 1.760 & 1.653 \\
Unavoidable vegetable food waste (UV) & 0.006 & 21.750 & 1.687 & 1.457 \\
Avoidable animal-derived food waste (AA) & 0.003 & 9.314 & 0.756 & 0.891 \\
Unavoidable animal-derived food Waste (UA) & 0.002 & 5.450 & 0.210 & 0.344 \\
Paper and board & 0.050 & 14.519 & 2.042 & 1.616 \\
Metal packaging & 0.002 & 13.415 & 0.213 & 0.556 \\
Plastic packaging & 0.007 & 19.415 & 0.524 & 0.753 \\
Other & 0.194 & 25.747 & 3.063 & 2.583 \\
\hline
\end{tabular}


SM Figure 1: Comparison of waste data sets before and after zero values replacement

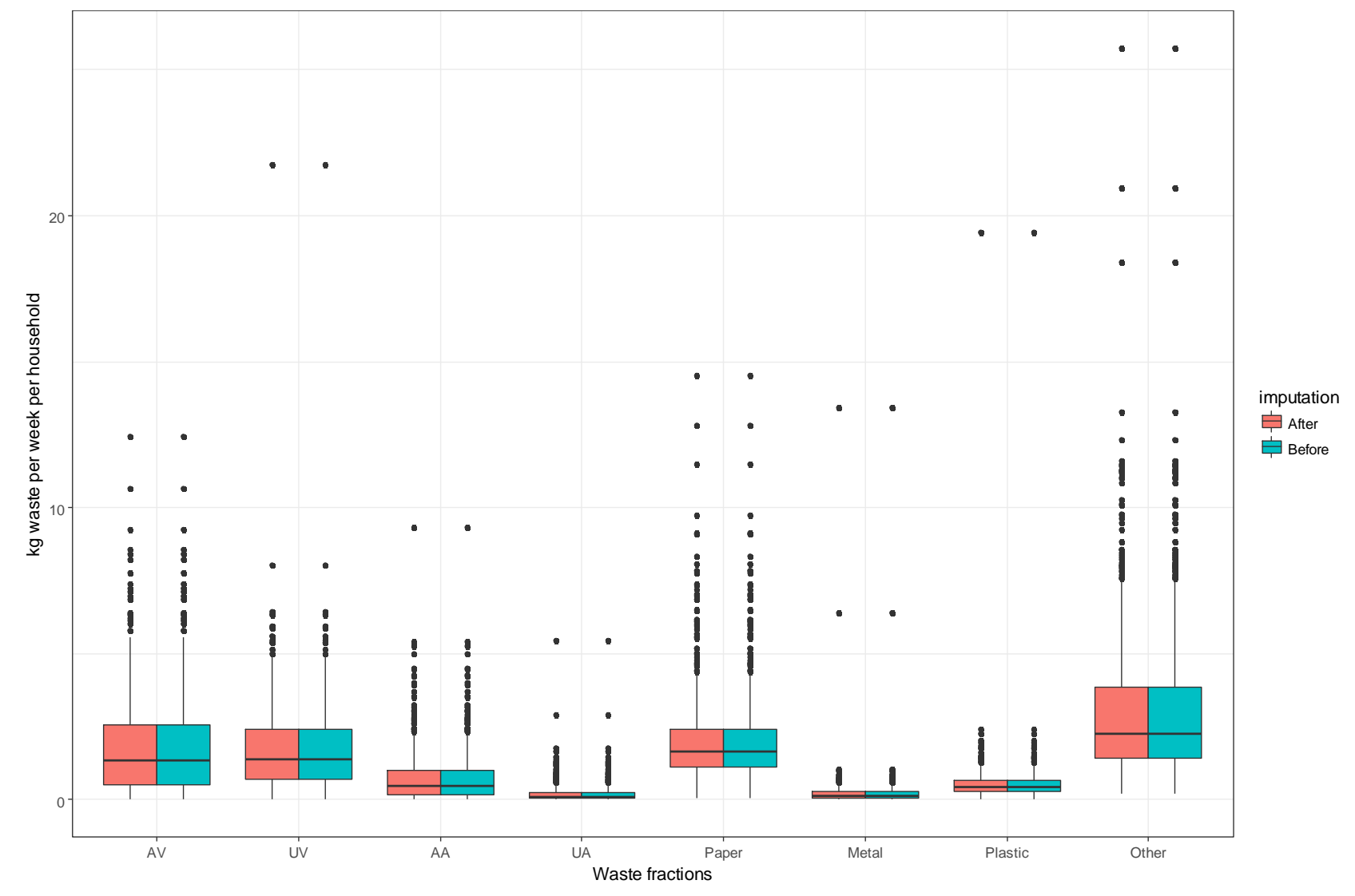

